\title{
Is there a relationship between constipation and time of enuresis: single center study in Referral Hospital, Tehran
}

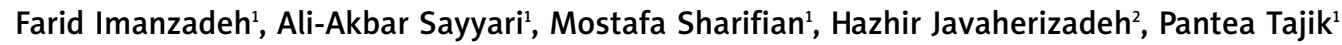 \\ ${ }^{1}$ Mofid Children's Hospital, Shahid Beheshti University of Medical Sciences, Tehran, Iran \\ 2Faculty of Medicine, Ahvaz Jundishapur University of Medical Sciences, Ahvaz, Iran
}

Prz Gastroenterol 2013; 8 (3): 176-179

DOI: $10.5114 / p g .2013 .36331$

Key words: constipation, enuresis, diurnal enuresis, nocturnal enuresis, children.

Address for correspondence: Hazhir Javaherizadeh, Assist. Prof. Faculty of Medicine, Ahvaz Jundishapur University of Medical Sciences, 6135873391, Iran, phone: +98 611 3337681, e-mail: hazhirja@yahoo.com

\begin{abstract}
Introduction: Constipation is one of the multiple factors that cause enuresis. The correlation between enuresis and constipation is well established. But there is limited research on the correlation of time of voiding and constipation.

Aim: To find a correlation between time of enuresis and constipation.

Material and methods: This cross sectional study was carried out in Mofid Children's Hospital, from January 2010 to June 2011. All patients with constipation or enuresis were included in this study and evaluated for both conditions. We classified cases according to time of enuresis in 3 categories. Data were analyzed by SPSS and Epi-info with $\chi^{2}$ and $t$-test. Value of $p$ below 0.05 was considered significant.

Results: In this study, 560 patients who visited a physician with constipation $(n=400)$ or enuresis $(n=160)$ were included. We investigated children with constipation for enuresis, and children with enuresis for constipation. Finally, constipation was present in 480 cases and enuresis in 289 cases. Duration of constipation was $9.60 \pm 7.1$ (1-42) weeks and duration of enuresis was $6.17 \pm 4.74$ (1-25) weeks. Of 160 patients with enuresis, 80 (50\%) had constipation. Of 400 patients with constipation, 129 had enuresis (32.25\%). There was a significant correlation between duration of constipation and duration of enuresis $(p<0.001$, Pearson test). Of 318 constipated boys, 148 (61.46) had enuresis. Of 162 girls with constipation, 61 (37.65\%) had enuresis. The rate of enuresis among constipated boys was significantly higher than girls $\left(p=0.0001, \chi^{2}\right)$. Of 560 patients, constipation and enuresis; only constipation; and only enuresis were found in 209 (37.32\%), 271 (48.40\%), and 80 (14.28\%) cases respectively. Conclusions: Duration of constipation was correlated with duration of enuresis. The rate of enuresis in constipated boys was significantly higher than in constipated females. We strongly recommend careful inspection of both conditions in each patient who presents with one of them.
\end{abstract}

\section{Introduction}

Constipation was defined as defecations occurring less than 3 times a week or at intervals longer than 3 days or any defecations with difficulties requiring increased effort during stool passage $[1,2]$. Constipation is one of the multiple factors that cause enuresis [3-6]. Constipation is under-diagnosed, and treated poorly [7]. Functional constipation is the most common cause of constipation in children [8]. Constipation has effects on the urinary system [9].

Enuresis has different classifications. Enuresis is classified as day time wetting and nocturnal enuresis.
In daytime wetting, enuresis occurs when the child is awake. In nocturnal enuresis, enuresis occurs when the child is asleep [10,11]. The correlation between enuresis and constipation is well established. But there is limited research on the correlation of time of voiding and constipation.

\section{Aim}

The aim of this study was to evaluate the pattern and frequency of enuresis among children with and without constipation. 


\section{Material and methods}

In this cross sectional study, all cases of constipation or enuresis were included. All patients were evaluated for both constipation and enuresis. Constipation was defined as hard defecation or defecation less than 3 times per week for more than 2 weeks [12]. In the standard classification, enuresis is categorized as day and night enuresis. In this study we classified enuresis in 3 categories in relation to the time of voiding. Our classification was different from the standard classification. Patients who wet their bed in the day were placed in group I. Patients who wet their bed at night were placed in group II. And patients who wet their bed at both day and night were placed in group III. We used this author-suggested classification, because we wanted to find more information if there is a difference according to time of enuresis.

\section{Statistical analysis}

Data were analyzed with SPSS version 16.0 (Chicago, IL, USA) and Epi-info version 6.4 (CDC). The $\chi^{2}$ and $t$-test were used for analysis. Value of $p$ below 0.05 was considered significant.

\section{Results}

In this study 560 (male 362, female 198) patients with constipation $(n=400)$ or enuresis $(n=160)$ as the

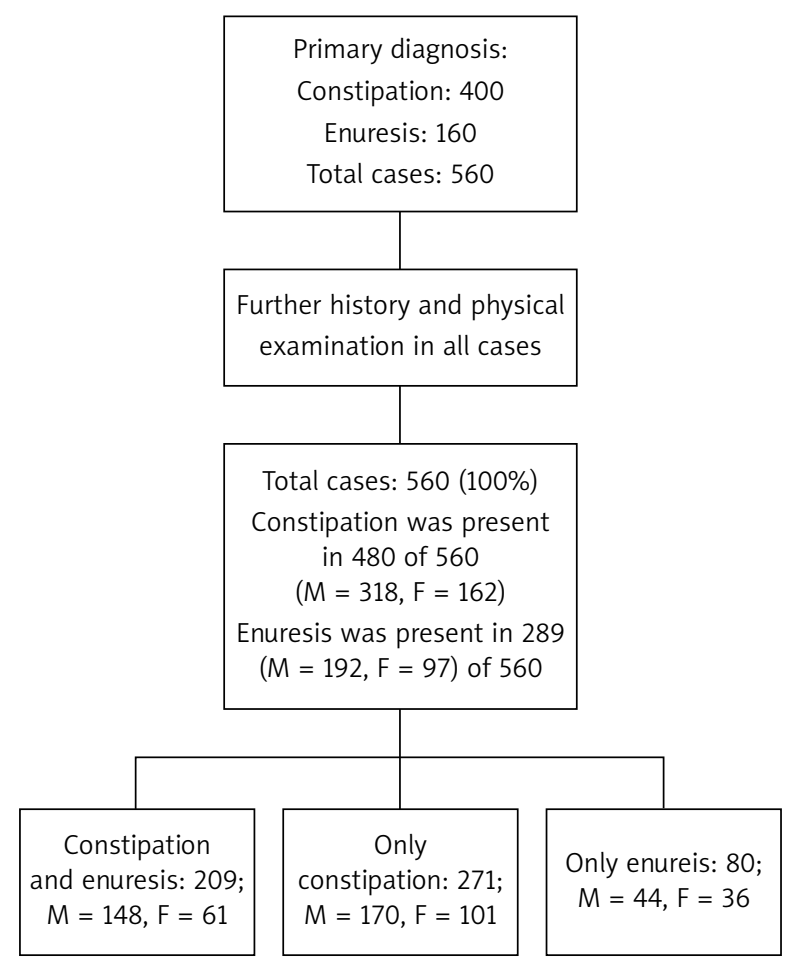

Fig. 1. Primary diagnosis and final findings in our study primary chief complaint were included. All patients with constipation was evaluated for enuresis and vice versa. Finally, constipation was found in 480 cases and there were 290 cases of enuresis (Figure 1).

From 560 patients, 537 (95.9\%) were aged 5-10 years and $23(4.1 \%)$ were aged $10-15$ years $(p<0.001)$. From 480 children with constipation, $318(66.25 \%)$ were male and $162(33.75 \%)$ were female $\left(p<0.001, \chi^{2}\right.$ test). Of 289 patients with enuresis, 192 were male and 97 were female. From 192 male patients with enuresis, $148(77.08 \%)$ had constipation and 44 did not have constipation. From 97 female patients with enuresis, $61(62.88 \%)$ had constipation (Figure 1). Of 318 constipated boys, 148 (46.55\%) had enuresis and 170 (53.45\%) were without enuresis. Of 162 constipated girls, $61(37.65 \%)$ had enuresis. The rate of enuresis among constipated boys was significantly higher than girls ( $p=0.0001, \chi^{2}$ test).

As seen in Table I, the rate of constipation was similar between different groups of time of enuresis ( $p=$ $0.09, \chi^{2}$ test).

Duration of constipation was $9.60 \pm 7.1$ (1-42) weeks and duration of enuresis was $6.17 \pm 4.74$ (1-25) weeks. There is a significant correlation between duration of constipation and duration of enuresis $(p<0.001$, Pearson test). Most of the patients in group III were male and this rate was significantly higher than other groups ( $p=0.003, \chi^{2}$ test) (Table II).

From 148 males with constipation and enuresis, most of the patients were in group $\|\left(p=0.0001, \chi^{2}\right.$ test). Of 44 enuretic boys without constipation, most of the patients were in group II (Table III). Of 61 enuretic

Table I. Constipation among children with enuresis

\begin{tabular}{lcc} 
Time of enuresis & Constipation & $N$ \\
\hline Group I & Yes & $33(70.21 \%)$ \\
\cline { 2 - 3 } & No & $14(29.79 \%)$ \\
\hline Group II & Yes & $113(68.49 \%)$ \\
\cline { 2 - 3 } & No & $52(31.51 \%)$ \\
\hline Group III & Yes & $63(81.81 \%)$ \\
\cline { 2 - 3 } & No & $14(18.19 \%)$ \\
$\quad p=0.09, \chi^{2}=4.79$ & &
\end{tabular}

Table II. Distribution of enuresis among male and female patients

\begin{tabular}{lccc} 
Group & Male & Female & Total \\
\hline I & $33(70.21 \%)$ & $14(29.79 \%)$ & $47(100 \%)$ \\
\hline II & $97(58.78 \%)$ & $68(41.22 \%)$ & $165(100 \%)$ \\
\hline III & $62(80.51 \%)^{*}$ & $15(19.49 \%)$ & $77(100 \%)$ \\
\multicolumn{2}{l}{${ }^{*} p=0.003, \chi^{2}=11.48$} &
\end{tabular}


Table III. Time of enuresis among patients with and without constipation

\begin{tabular}{lcccccc} 
Sex & Constipation & $\begin{array}{c}\text { Group I } \\
n(\%)\end{array}$ & $\begin{array}{c}\text { Group II } \\
n(\%)\end{array}$ & $\begin{array}{c}\text { Group III } \\
n(\%)\end{array}$ & $\begin{array}{c}\text { Without enuresis } \\
n(\%)\end{array}$ & $\begin{array}{c}\text { Total } \\
n(\%)\end{array}$ \\
\hline Male & Yes & $24(7.55)$ & $70(22.01)^{*}$ & $54(16.99)$ & $170(53.45)$ & $318(100)$ \\
\cline { 2 - 7 } & No & $9(20.45)$ & $27(61.36)^{*}$ & $8(18.19)$ & 0 & $44(100)$ \\
\hline \multirow{2}{*}{ Female } & Yes & $9(5.55)$ & $43(26.55)^{*}$ & $9(5.55)$ & $101(62.35)$ & $162(100)$ \\
\cline { 2 - 7 } & No & $5(13.88)$ & $25(69.45)^{*}$ & $6(16.67)$ & 0 & $36(100)$ \\
\hline Total & Yes & $33(6.88)$ & $113(23.55)$ & $63(13.12)$ & $271(56.45)$ & $480(100)$ \\
\cline { 2 - 7 } & No & $14(17.5)$ & $52(65.00)$ & $14(17.5)$ & 0 & $80(100)$
\end{tabular}

${ }^{*} p<0.05$

females with constipation, most of the patients (43/61) were in group $\|$ ( $p=0.0001, \chi^{2}$ test $)$. Of 36 enuretic females without constipation, 52 were in group $\|(p=$ $=0.00001, \chi^{2}$ test). As a result, with or without constipation most patients were in group II (nocturnal enuresis).

\section{Discussion}

In our study from 480 patients with constipation, 209 (43.54\%) had enuresis. Incidence of enuresis in encopretic children has been reported between $21.6 \%$ and $50.4 \%$ in different studies $[13,14]$.

In our study, two groups of cases were studied: in children who visited for treatment of enuresis (160 cases), frequency of constipation was about $50 \%$; in children who visited for treatment of constipation (400 cases), we found that 129 also had enuresis (32.25\%).

The difference between methods of study may be the result of this difference. In a cross sectional study among 277 children with enuresis, according to parental reporting $14 \%$ had constipation and clinical assessment found $36 \%$ with constipation. Parents are often unaware about constipation in their enuretic child [15]. In our study from 160 patients with enuresis as the chief compliant, constipation was found in 80 (50\%) of them. This higher rate of constipation among enuretic patients may be due to failure of the primary physician to detect constipation or low knowledge of parents about constipation.

In a study by Çayan et al., they found that incidence of constipation among enuretic patients (7.06\%) was significantly higher than non-enuretic patients (1.45\%). They studied only cases of nocturnal enuresis [16]. In our study, from 289 enuretic patients, constipation was found in 209 (72.31\%). This finding showed that the rate of constipation in our enuretic cases was higher than enuretic cases in the Çayan et al. study [16]. Loening-Baucke reported that from patients with constipation, $29 \%$ had diurnal enuresis and $34 \%$ had nocturnal enuresis. Following successful treatment of constipation, $89 \%$ of those with diurnal enuresis and $63 \%$ with nocturnal enuresis showed complete resolution of enuresis [17].
In our study, of 318 constipated boys, 148 (61.46\%) had enuresis. Of 318 boys with constipation, 24 (7.55\%) had enuresis in the day; 70 (22.01\%) had enuresis at night; and 54 (16.99\%) had enuresis in the day and night. From 162 constipated girls, 37.65\% had enuresis. Of 162 girls with constipation, 9 (5.55\%) had enuresis in the day; 43 (26.55\%) had enuresis at night; and 9 (5.55\%) had enuresis in the day and night. However, we used a different classification in this study, but in two studies nighttime enuresis was more than day time enuresis.

Encopresis is a modifiable risk factor for nocturnal enuresis [18]. In our study, more than half of the patients had this risk factor. Our physicians must be aware of this high rate of constipation among Iranian enuretic patients.

Kasirga et al. studied 38 cases of chronic functional constipation and 31 healthy children as a control group. They did not find significant differences in incidence of enuresis between case and control groups. They studied cases of nocturnal enuresis [19]. In our study, we found a correlation between duration of enuresis and duration of constipation. However, our study was different from that of Kasirga et al., because they studied enuresis in normal children and children with constipation. We studied constipation in enuretic children and enuresis in constipated children.

In our study we included all types of enuresis related to time of occurrence. But one of the limitation of this study was that it was cross sectional and we have no follow-up. Parents did not know the exact time of voiding.

\section{Conclusions}

In this study, we found a correlation between duration of constipation and duration of enuresis. The rate of constipation among enuretic children in our study was higher than in other studies. It is recommended to carefully examine for constipation in each child presenting with enuresis and for enuresis in each child presenting with constipation to design the best treatment plan for the child. 


\section{Acknowledgments}

Data was used in this paper was from residency thesis of Dr. Pantea Tajik; and financial support was provided by research affairs of Shahid Beheshti University of Medical Sciences.

\section{References}

1. Talley NJ, Jones M, Nuyts G, et al. Risk factors for chronic constipation based on a general practice sample. Am J Gastroenterol 2003; 98: 1107-11

2. Reich M, Iwańczak B. Constipation in children - causes, diagnostics and treatment. Adv Clin Exp Med 2007; 16: 443-56.

3. Romanczuk W, Korczawski R. Chronic constipation: a cause of recurrent urinary tract infections. Turk J Pediatr 1993; 35: 181-8.

4. Levine MD. The school child with encopresis. Pediatr Rev 1981; 2: $285-9$

5. ÕRegan S, Yazbeck S, Hamberger B, et al. Constipation a commonly unrecognized cause of enuresis. Am J Dis Child 1986; 140: 260-1

6. Patel DR, Pratt HD. Encopresis. Indian J Pediatr 1999; 66 439-46.

7. Dohil R, Roberts $\mathrm{E}$, Jones KV, et al. Constipation and reversible urinary tract abnormalities. Arch Dis Child 1994; 70: 56-7.

8. Reich M, Iwańczak B. Analysis of the commonest causes and symptoms of chronic constipation in children. Prz Gastroenterol 2010; 5: 349-55.

9. Imanzadeh F, Sayyari AA, Sharifian M, et al. Study of factors affecting resolution of urinary tract infection following treatment of constipation in Iranian children who visited a tertiary referral hospital. Prz Gastroenterol 2012; 7: 78-80.

10. Nevéus T, von Gontard A, Hoebeke P, et al. The standardization of terminology of lower urinary tract function in children and adolescents: report from the Standardisation Committee of the International Children's Continence Society. J Urol 2006; 176: 314-24.

11. Fritz G, Rockney R, Bernet W, et al. Practice parameter for the assessment and treatment of children and adolescents with enuresis. J Am Acad Child Adolesc Psychiatry 2004; 43: 1540-50.

12. Constipation Guideline Committee of the North American Society for Pediatric Gastroenterology, Hepatology and Nutrition. Evaluation and treatment of constipation in infants and children: recommendations of the North American Society for Pediatric Gastroenterology, Hepatology and Nutrition. J Pediatr Gastroenterol Nutr 2006; 43: e1-13.

13. Clavero AM, Toro TJ. Enuresis and encopresis: their relationship. An Esp Pediatr 1993; 39: 320-4.

14. Uguralp S, Karaoglu L, Karaman A, et al. Frequency of enuresis, constipation and enuresis association with constipation in a group of school children aged 5-9 years in Malatya, Turkey. Turk J Med Sci 2003; 33: 315-20.

15. McGrath KH, Caldwell PHY, Jones MP. The frequency of constipation in children with nocturnal enuresis: a comparison of parental reporting. J Paediatr Child Health 2008; 44: 19-27.

16. Çayan S, Doruk E, Bozlu M, et al The assessment of constipation in monosymptomatic primary nocturnal enuresis. Int Urol Nephrol 2001; 33: 513-6.
17. Loening-Baucke V. Urinary incontinence and urinary tract infection and their resolution with treatment of chronic constipation of childhood. Pediatrics 1997; 100: 228-32.

18. Sureshkumar P, Jones M, Caldwell PHY, Craig JC. Risk factors for nocturnal enuresis in school-age children. J Urol 2009; 182: 2893-9.

19. Kasırga E, Akil I, Yılmaz Ö, et al. Evaluation of voiding dysfunctions in children with chronic functional constipation. Turk J Pediatr 2006; 48: 340-3. 